\title{
LUNDU, PADÊ, APOCALIPSE CUÍR - ENTREVISTA COM TATIANA NASCIMENTO DOS SANTOS.
}

\author{
Marcelo Spitzner*
}

Essa entrevista foi realizada através da troca de imeios, iniciou em 04/03 e terminou no dia 23/04 - dia de Ogum, que como bem lembra a tate é o orixá da tecnologia como instrumento de trabalho, e também de afetos, mesmo quando os corpos estão deslocados no espaço. Foram em torno de 30 trocas de imeios enriquecidos por respostas, trocas de ideias e experiências. A publicação dessa conversa com Tatiana realiza um desejo de compartilhar espaços de escritura ${ }^{1}$ com essa pessoa cheia de afetos, forte e desafiadora, como boa filha de Iansã! Além de filha de Iansã, Tatiana Nascimento, a tate, é doutora em Estudos da Tradução (UFSC). Licenciada em Letras - Português (UnB). Poeta; tradutora; copidesque. Editora-fundadora da padê editorial. Compositora, cantora, slammer. Suas áreas de interesse e atuação vão desde poesia, produção textual, culturas negras afrodiaspóricas passando pela tradução, educação antirracista, sapatonice/lesbiandade, transfeminismo.

1- (Marcelo Spitzner) - tate, você PODERIA NOS CONTAR UM POUCO DE SUA TRAJETÓRIA, NA MILITÂNCIA E NOS ESTUDOS ACADÊMICOS, NA PRODUÇÃO ARTÍSTICA.

(Tatiana Nascimento) - hoje é o4 de março de 2017. o mês de março é muito simbólico pros movimentos sociais por causa do dia 08 - “internacional das mulheres". eu comecei a atuar em coletividades políticas de luta no ensino médio, e tive a sorte de conhecer o feminismo anarquista pela cena hardcore de brasília, antes de entrar na universidade, com uns 20, 21 anos, quando comecei a tocar baixo em bandas de/com mulheres ("toda dor do mundo" e depois "silente", com alguns projetos paralelos menos frutíferos no meio). esse começo de atuação feminista marcou também minha produção como publicadora - eu já era zineira desde os 17, fazia um zine que hoje vejo como meio gótico, meio literário, que se chamava lathspell (sim, eu adoro a coleção do tolkien). mas quando comecei a me envolver com outras ativistas questionando os lugares destinados a mulheres na produção cultural do dfé que comecei a escrever zines mais meus, com mais textos autorais,

\footnotetext{
${ }^{1}$ Esse desejo vem desde 2013, quando fizemos uma disciplina no Programa de Pós-graduação em Inglês da UFSC e a professora Claudia de Lima Costa nos pediu que resenhássemos juntes o livro Gaga Feminism, de J. Jack Halberstam. Chegamos a pensar de pedir autorização a Halberstam para publicarmos a resenha com uma tradução do Manifesto Gaga, que encerra o livro. Quem sabe um dia!

"Professor de Estudos Literários da Universidade Federal Rural da Amazônia, Campus de Tomé-Açu. Email: marcelospitzner@gmail.com.
} 
e fazer esses zines circularem - eu e alice gabriel, minha parceira de banda na época (isso era o começo dos 2000) montamos uma coletiva chamada la carnissa que tinha um zine de mesmo nome. a coletiva aliás ganhou força por causa do zine, que veio primeiro. daí veio o corpuscrisis, que foi um outro espaço muito importante e maior, com mais alcance nacional e intergalático (rio muito escrevendo isso mas era essa nossa megalomania, e na real a coisa correu-mundo mesmo), meu contato com o ativismo lésbico feminista e com o movimento de mulheres negras, e no meio disso tudo a poesia. que tava lá fazia tempo. mas precisei caminhar essas jornadas de fortalecimento entre coletividades pra publicar, compartilhar, falar em público.

hum, sim, e no meio disso tudo, também, em 2004 mais precisamente, comecei a cursar português na unb, na primeira turma de cotas étnico-raciais, e isso foi um outro giro. inclusive de me colocar em um deslugar estranho, que desde então me acompanha, de me sentir vestindo aquele chapéu de duas cores de exu. eu me entendo, e me intento, e me exercito me experimento como uma intelectual muito agitada. e uma agitadora muito cabeçuda. mas tentei umas outras três graduações antes de conseguir concluir essa, que levou seis anos longos, difíceis, conflituosos, de muito enfrentamento; não só por ser negra de pele clara num sistema recém-inaugurado de cotas, não só por ser lésbica ativista, não só por esboçar produzir conhecimento (fazer pesquisa) a partir desses sinalizadores de raça, sexo-gênero: mas porque algumas subjetividades contrahegemônicas são talhadas com textualidades igualmente contrahegemônicas. em 2014, na defesa do doutoramento, eu ouvi a acusação de que minha tese não era acadêmica. benzajah a banca era muito crítica e comprometida com a demolição dos muros acadêmicos, seu hermetismo, suas formas caducas, e a tese foi aprovada, aplaudida, questionada de forma frutífera y construtiva... mas eu já tinha ouvido isso antes, você é muito panfletária e aqui é a academia . assim como já ouvi em movimento social que sou muito academiqueira. enfim, o chapéu de exu tem me servido. não é um lugar cômodo de ocupar, a academia. nem prazenteiro. e é pouco interessante. mas eu sou um ser pensante, reflexivo, aquariano, analítico. sempre fui. achar que uma tradição curriculista, catedrática, formalista pode enquadrar isso é vão, pra mim. eu quero que os sistemas formais de escolarização derretam. desmanchem. então ocupei a academia como uma agitadora (e ainda ando ocupando, de quando em vez; agora no segundo semestre de 2017 vou ministrar, de novo, feminismos e teoria queer, no campus de planaltina da unb, que é mais relacionado à educação do campo, que fica na periferia do distrito federal, que tem agrupamentos de estudantes quilombolas, sem-terra.)

2- (M.S) - VOCÊ TEM TRABALHADO
BASTANTE COM POESIA E PERFORMANCE...
TEM PRODUZIDO LIVROS ARTESANAIS. COMO
FOI QUE VOCÊ COMEÇOU E O QUE TEM
MOTIVADO O SEU TRABALHO EM TERMOS
ESTÉTICOS, TEMÁTICOS? HÁ UMA PROPOSTA
POLÍTICA NESSE TRABALHO OU APENAS UMA
MOTIVAÇÃO ARTÍSTICA?

(T.N) - o que eu tenho alcançado hoje pelo trabalho com poesia e performance, que 
tá misturado cada vez mais fundo com o de publicação desde que sonhei a padê editorial com a bárbara esmenia em 2015 (finalmente fundada em 2016 e hoje com 4 títulos lindos e 2 a caminho pra julho/2017), é kármico, pra mim. que a gente recebe aquilo que oferece. que existe retribuição e reconhecimento praquilo que é feito com amor. eu sou um bicho selvagem na maior parte do tempo: calada, introspecta, sonho de vulcão mesmo. poesia é um jeito que achei de me comunicar, de mostrar a pérola que tinha ficado ali sendo forjada pela concha. é uma doidera que quanto mais eu faça poemas maravilhosos menos eu fale, mas é assim mesmo que tem sido e vai que mude logo, por enquanto está. que chegue em outras pessoas recebido com afeto, com reconhecimento, valorização, remuneração às vezes, é um alívio: responde o intuito comunicador que eu tenho com minha poesia. mas antes de comunicar eu já tava envolvida com as palavras que se amontoam de um jeito específico, como é a poesia ("um amontoado de palavras", pra alice gabriel de quem falei ali em cima), faço poesia desde os 10, 11 anos. ganhei concursinho de poesia na escola, fama de escrevedora-de-cartas-de-amor-entre-amigas na mesma época. na adolescência os temas mudaram do afeto sentido dentro do peito sobre quem me rodeia pro tudo que rodeia, como rodeia, como não toca, como não muda, como machuca, "poesia política". mas hoje vendo muita obra de poesia negra que é condenada como não-poesia porque tem um compromisso de denúncia imprescindível eu fico pensando. tanto tempo de colonialidade, 300 anos de escravização física, mental, meio milênio de protagonismo não-negro, protagonismo de narrativas não-negras sobre a negritude inclusive (o que é a antropologia no brasil, a tradicional, se não esse constante falar do outro não-branco por bocas brancas?), o povo preto na diáspora é que tem que escrever sua história. seja que história for. nesse sentido pagode anos 90, pra mim, é político demais, porque os grupos chamavam soweto, raça negra, só pra contrariar, e falavam de amor. quando passamos 300 anos sendo exploradxs sexualmente, com fazendas de estupro, pra homens negros estuprarem mulheres negras pra produzirem mais escravizadxs. então não é político falar de amor? é sim (e óbvio não isento de crítica esse falar - que muito heterocêntrico, que muito românticocêntrico). e nesse sentido há alguma forma de fazer arte sem motivação política? mesmo que essa seja de reforçar as estruturas invisíveis da política hegemônica? tem não. o que tem motivado meu trabalho estética e políticamente (uma coisa misturada pra mim) é reinventar minha linguagem de pessoa preta na diáspora desde a dissidência sexual. buscar um jeito de me escrever, minhas histórias percepções as histórias que o vento me sopra que uma senhora conta no ônibus que alguém me entrega num sonho que uma notícia de jornal esconde, bonitamente no espaço, sinteticamente-sintaticamente, geometricamente-fonologicamente, metaforicamente, silenciosamente. a palavra é uma tecnologia que me impressiona. me movimenta (com toda sua precariedade, pretensão de diferenciar pessoas humanas de não-humanas... é uma ferramenta, enfim). 
3- (M.S) - VOCÊ NARROU SOBRE SUA TRAJETÓRIA EM ALGUMAS COLETIVIDADES, COMEÇANDO PELO FEMINISMO ANÁRQUICO, PASSANDO PELO ATIVISMO LÉSBICO E PELO MOVIMENTO DE MULHERES NEGRAS... VOCÊ PODERIA NOS CONTAR SOBRE ESSA DIVERSIDADE DE COLETIVIDADES, SUAS PAUTAS ESPECÍFICAS E EM QUE PARTILHAM DE PROJETO POLÍTICO E EPISTEMOLÓGICO? AO MESMO TEMPO, QUAL A IMPORTÂNCIA DO SENTIDO DE PERTENÇA E DOS AFETOS PARA A TRANSFORMAÇÃO DO MUNDO?

(T.N) - eu comecei mesmo no movimento estudantil do ensino médio (na época era segundo grau), e tive contato com um coletivo marxista internacionalista. por causa disso fui pra cuba num evento de juventude em que aprendi muito sobre autonomia, sobre riqueza e pobreza, sobre direitos fundamentais e garantia estatal, e sobre: gente preta na diáspora. eu nem chamava assim na real, mas me lembro de ficar impressionada com a quantidade de pessoas negras em havana, como eu nunca tinha visto alguma coisa assim nos meus então 16 anos de vida em uma brasília extremamente segregadora racial e espacialmente. na real só ia encontrar tanta gente preta de cabeça erguida assim como vi em cuba quando fui pra salvador pela primeira vez, em 1999. também o ano em que entrei no vegetarianismo como modo vida.e só anos depois fui entender o que essas duas cidades tinham a ver com ancestralidade negra de um jeito mágico que, enfim, cabia em outra prosa.

mas ao longo da caminhada é que fui me conectando com essas outras coletividades já mencionadas e uma formação como alfabetizadora na EJA primeiro, e depois na licenciatura da unb, conheci algumas coisas importantes de pedagogia crítica e especialmente o trampo do paulo freire, que foi a porta pra começar a pensar formalmente os sistemas de opressão, e como tão conectados. no começo da graduação, sendo da primeira turma de cotas étnico-raciais de uma federal no brasil (2004 na unb), um professor que eu já conhecia de ativismos anteriores (no corpuscrisis, uma coletiva de micropolítica feminista muito pulsante, radical, simples, afetiva também de brasília) ofereceu uma disciplina em homenagem à primeira turma de cotas e a ementa era basicamente de autoras negras. aí eu conheci algumas obras, como a de audre lorde, e tive mais contato com a bell hooks, uma autora que eu já conhecia de ser rata de uma biblioteca grande em brasília na qual minha mãe, bibliotecária, trabalhava.

enfim, a linha cronológica tá meio bagunçada e tô ressaltando algumas descobertas teóricas porque fortaleceram um pensar das ressonâncias que existem entre as subjetividades dissidentes, sejam elas negras, ou desde a dissidência sexual, anticapitalistas... o encontro desses pensamentos é que alimentou o pensar criticamente minhas práticas, minhas inserções, meu lugar de classe, de raça, de sexo, de escolaridade. porque eu já tava uns anos antes em práticas ativistas sem sacar direito o que é que me incomodava em alguns espaços, o que era a sensação de despertencimento ou angústia quando alguma coisa racista acontecia num contexto anticapitalista, por exemplo, e eu ainda não tinha conseguido eu mesma elaborar uma linguagem que me permitisse apontar a angústia naquilo, produzir uma resposta crítica e/ou propositiva que não fosse me afastar da 
coletividade (especialmente quando penso no comecinho do meu rolet autônomo, cena hardcore, tocar com outras minas em espaços de domínio heterossexista pra caramba...) - algumas experiências tão doloridas a ponto de expulsar as pessoas ofendidas da coletividade, ao invés de surgir como oportunidade de repensar aquela comunidade, aqueles laços, os privilégios subjacentes que construíam as diferenças como abismos ao invés de pontes, sabe?

algumas vezes as insistências no privilégio rompem a força do afeto. isso é triste. a máquina política-externa-social atropela o coração, o vínculo. tenho pensado muito nisso na real, porque esse tem sido um momento (por controverso que pareça) de muita solidão pra mim, ao mesmo tempo em que tô tão figura pública, a coisa da palavra (como poeta, como cantora ${ }^{1}$, como editora) me conectando com tantas outras pessoas. não sei bem como responder essa pergunta hoje, exatamente hoje, tive um dia bem frutífero com muitas presenças amadas pra fazer projetos (esses públicos) maravilhosos, mas ao mesmo tempo foi um dia de não ter com quem conversar sobre como meu coração bateu mais forte com um determinado encontro. eu só sei que somos mamíferxs né? tenho aprendido muito com outrxs mamíferxs que essa classe de seres é gregária. costuma se cuidar. costuma formar laços de amor, comensalidade, território, erotismo, parentalidade. inclusive interespécie! talvez isso esteja nos dizendo alguma coisa há algum tempo, que tenhamos esquecido de

\footnotetext{
${ }^{1}$ Ver tatiana nascimento performando aqui: https:// www.youtube.com/watch?v=gXsjYxbFNcU (NdE)
}

entender depois que inventamos esse trem de linguagem né?

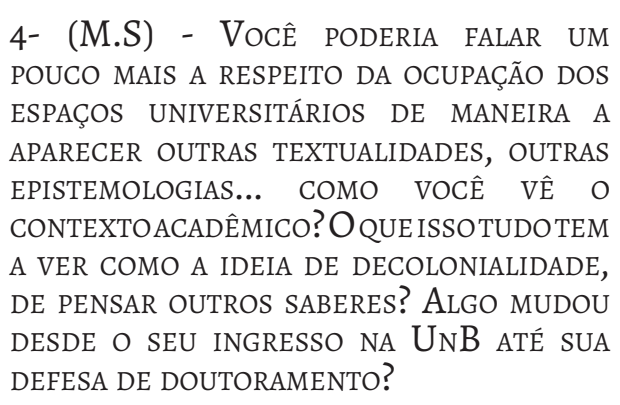

(T.N) - eu estou afastada da academia há uns três anos... e meio. sei que tem algumas brechas, que há programas de literatura em que é possível produzir teses-romances, tem o programa conexão de saberes na unb que tem feito um trabalho lindo de abertura do cânone universitário à produção epistêmica dxs mestras e mestres de saberes tradicionais, e acho que deve ter muito mais coisa linda acontecendo. tipo, gosto muito da ideia de mestrado profissional (a ufrb tem um em educação do campo que parece cheio de possibilidades importantes de transformação, e tem um diálogo lindo com a luta pela reforma agrária, pelo que vejo nas notícias sobre o curso). além de demandar um envolvimento necessário com uma realidade externa à academia de forma extensionista permite também que o produto final seja outra coisa que não um texto em prosa acadêmica: pode ser um documentário, pode ser material didático... isso é massa demais! mas não sei se essas exceções ameaçam a regra não, viu? nos 10 anos em que fiquei na academia formalmente matriculada, de 2004 a 2014, algo muito importante mudou: a quantidade de energia que eu tinha pra trocar com esses 
ambientes diminuiu (é verdade, y é quase uma piada!), e eu aprendi (rapidão eu aprendi isso, na real) que o espaço ganha mais com as nossas presenças (pesquisadorxs sapatão, viado, pretx, trans, mentes insubmissas y corpos que incomodam as normas, gente com ritmo de aprendizado diferente do esperado, corpos indomáveis) do que ganhamos do espaço - mesmo quando bolsistas! mesmo assim.

tenho acompanhado com muita alegria o aumento vertiginoso de debates anticoloniais e/ou da decolonialidade mais através das produ-sãs de amigxs que tão nas universidades e produzindo desde aí, acho inspirador o trabalho do wanderson flor na unb, $\mathrm{da}$ aline matos na ueg, nina ferreira que saiu do df há uns meses foi pra sampaulo, angela donini no rio, sara elton panambi que sei lá por onde anda agora, viviane vergueiro e tito carvalhal em salvador, kika sena na unb, magô tonhon em sampaulo, jota mombaça viajando por tantos cantos, trabalhos que também tão dinamitando os muros da academia desde dentro, inspirador e lindo e apocalíptico: porque aponta que alguns aspectos desse mundo têm que ser destruídos mesmo pra que outras coisas possam nascer. é a dança trimúrti do universo né? vishnu dá lugar a shiva que dá lugar a brahma que dá lugar a vishnu que dá lugar a shiva que dá lugar... (tão importante que a gente não se perca nesse movimento: ele não é só shivaísta)

tenho pensado muito nas outras vias. a academia é meio vishnu, conservadora né. perdeu faz tempo o que quer que tenha de brahmânica, de criativa. e quem tava fora faz tempo entrou viradx em shiva mesmo: pra destruir. des-cons-tru-ir, como lá diz. num esqueço nas ocupações contra a pec do fim do mundo em novembro de 2016: teve assembleia estudantil na faculdade de comunicação da unb pra decidir pela ocupação ou pela greve (ou o quê), e olha em 2004 a faculdade de comunicação era muito branca, um curso majoritariamente de elite, de gente branca. pois nessa assembleia com 200 e tantxs, 300 estudantes, mais da metade era negrx, e a coordenação da assembleia era majoritariamente negrx, lgbt, periférica! isso foi uma coisa inédita nos meus anos de unb e acho que nos anos da unb toda, na real... muito impressionante mesmo.

então isso também mudou: quando o quilombo ocupa a casa-grande, ao menos os móveis vão mudar de lugar. e sempre tem a possibilidade de fogo no horizonte. sempre. as cotas não são um mecanismo de inclusão de corpos dóceis. não são uma medida de repensar disparidades criadas por inacessos econômicos (e aqui importante lembrar que a fundação da pobreza no brasil é a constituição do racismo escravocrata, ou seja, o racismo inventa sim a pobreza no brasil e não o contrário). são uma jeito de dizer que os dias de casa-grande acabaram. que ou escrevemos nossa história, pensamos nossos processos, teorizamos nossas cosmovisões, ou os livros vão alimentar o fogo (acho que tô meio shivaísta hoje).

5- (M.S) - Por FAlar em Seu Doutorado, EU LEMBRO QUE NOS CONHECEMOS EM UMA DISCIPLINA NA UFSC E QUE APRENDI MUITAS COISAS COM VOCÊ... EU LEMBRO DE VOCÊ FALAR A RESPEITO DE TRADUÇÃO FEMINISTA, DE LETRAMENTO... OU MELHOR, DA TRADUÇÃO COMO POLÍTICA DE LETRAMENTO LÉSBICO 
Negro Feminista. Enfim, poderia nos FALAR SOBRE TRADUÇÃO, LETRAMENTO... QUE CONCEITO DE TRADUÇÃO VOCÊ TRABALHA E QUAL A IMPORTÂNCIA DA TRADUÇÃO PARA AS POLÍTICAS FEMINISTAS, PARA OS/AS SUJEITAS/ OS RACIALIZADAS/OS E DAS SEXUALIDADES Dissidentes? Poderia localizar o Debate OU OS DEBATES ESPECÍFICOS QUE PASSARAM A FORMAR PARTE DA SUA AGENDA TEÓRICA E POLÍTICA, OS TERMOS CHAVES EM TORNO DOS QUAIS GIRA SEU PROJETO ATUAL DE REDEFINIÇÃO DAS DINÂMICAS DE GÊNERO, RAÇA, SEXUALIDADE.

(T.N) - marcelo, a temporada na ufsc me trouxe três grandes amizades com pessoas-humanas, uma sendo você! com quem, além de ter um respiradouro de afeto numa cidade que pode ser muito difícil em termos de relações humanas interraciais, aprendi também coisas acadêmicas muito importantes, especialmente sobre tradução cultural. essa era uma abordagem da qual eu não tinha ouvido falar antes. e isso me alargou um pouco os horizontes pra pensar de forma mais séria/metodológica a tradução como um processo bem maior que os textos escritos mesmo, processo que pode ter uma reverberação política e cultural transformadora. minha tese foi nessa pegada, de juntar as três paixões teóricas que eu tinha na época (teoria feminista lésbica negra, tradução feminista e os novos estudos do letramento) pra pensar minha trajetória como ativista-tradutora no compartilhar de textualidades lésbicas negras entre pares, o alcance disso, as possibilidades de transformação, a constituição de espelhos subjetivos pela evocação dessas referências: daí minha pira da metáfora da tradução como o abebe, o espelho em que Oxum se mira não porque é vaidosa, como as leituras hegemônicas heteronormativas dos itans costumam sugerir, mas porque reconhece nele uma ferramenta de autoconhecimento poderosa.

colei também na proposta de sonia alvarez da tradução feita em abya yala (américa latina y caribe) como tráfico de informações entre subjetividades feministas, na forja de uma estratégia anticolonial de produzir conhecimento, fazer esse conhecimento circular. e a primeira teórica de tradução feminista que me encantou muito foi bárbara godard, que já passou desse plano, e escreveu sobre a tradução como uma poética da diferença, do encontro entre tradutora y traduzida, ressaltando em como, nesse encontro, mulheres* reelaboram linguagem, uma coisa que tinha sido roubada dessas sujeitas. eu mesmo colando na wittig quando diz que as lésbicas não são mulheres, que estamos fora da economia hetero(cis)sexista da subserviência ao masculino, admiro muito essa pensada da godard, de mirar o que é que tem de possível e de específico na tradução feita por mulheres, que remodelações textuais, infrações, invenções, isso pede: na falta de uma linguagem que não seja aquela do heterocispatriarcado.

isso foi na época da pesquisa né, agora mais recentemente tenho tido a alegria y sorte de encontrar teorização desde a diáspora pra pensar as especificidades dos projetos negros de tradução, e a importância disso na vastidão transatlântica - denise carrascoso, na UFBA, é uma das teóricas que tenho lido, e também a jess oliveira, que tá estudando na UFSC agora e já produzindo teoria linda, preta, transfeminista! pra mim, que constituí muito da minha performance de sapatão poeta a partir da leitura de teoria em prosa y 
em poesia de pensadoras como audre lorde, cheryl clarke, e mais recentemente dionne brand, a tradução sempre foi um espelho das possibilidades: de onde me enxergar. de onde enxergar as lesbiandades negras em diáspora. uma escola de subjetividade mesmo. e cada vez mais só me faz sentido pensar a diáspora desde a dissidência sexual e vice-versa, porque tô metida em comunidades negras lgbtqi, me envolvo com projetos $\mathrm{com} /$ pra essas comunidades, me interesso pelo que tá sendo escrito, desenhado, cinematografado por essas comunidades (jota mombaça, michelle matiuzzi, marissa lobo, njideka stephanie, porsha o., wanderson flor, denise botelho, aline matos são algumas dessas inspirações poéticas/políticas/ epistêmicas).

mas eita que difícil essa última parte da pergunta. difícil de ser tão precisa. "localizar o debate ou os debates específicos que passaram a formar parte da sua agenda teórica e política, os termos chaves em torno dos quais gira seu projeto atual de redefinição das dinâmicas de gênero, raça, sexualidade."?

alguns termos-chave são cura; autoamor; água limpa; reforma agrária baseada na agricultura familiar e produção orgânica; compartilhamento de nossas experiências de prazer e resistência; antirracismo transfeminista; antiespecismo anticapitalista; auto-organização e organização popular na base do faça-você-mesmx, abaixo, e à esquerda; caminharmos pelo planeta sem estragar tudo pra nossa espécie nem pras outras.

alguns. mas acho que na próxima vez faço um mini-dicionário. ou um zine!
$(\mathrm{M}, \mathrm{S})$ - tate, ficamos no aguardo desse mini-dicionário ou zine! Certeza que será muito eficaz para todas/os nós.

6- (M.S) - BOM, CHEGANDO AO FINAL DE NOSSA ENTREVISTA, QUE COMEÇOU NA SEMANA DO DIA DAS MULHERES (08/03), PASSOU PELA SEMANA DO DIA DE COMBATE À DISCRIMINAÇÃO RACIAL (21/03) E TERMINA NO DiA DE JoRge, De Ogum (23/04), O SENHOR DA GUERRA, O FERREIRO (ACHO PROVIDENCIAL ENTRELAÇAR NOSSA CONVERSA COM ESSAS DATAS), GOSTARIA DE PEDIR PARA VOCÊ FALAR UM POUCO SOBRE O SURGIMENTO Da Padê Editorial, do SEU livro Lundu, DAS COLEÇÕES QUE HOMENAGEIAM AS YABÁS. COMO OCORRE O PROCESSO DE CONSTRUÇÃO DE ESTÉTICAS NEGRAS, DIASPÓRICAS, LÉSBICAS DENTRO DA SUA COMPOSIÇÃO E DAS PESSOAS QUE COMPARTILHAM COM VOCÊ ESSE PROJETO POÉTICO-POLÍTICO? ENFIM, POR QUE ESCREVER E O QUE A ESCRITURA EXPRESSA NO CONTEXTO DAS SUbaltenidades? Ao TE FAZER ESSA PERGUNTA, PASSA-ME PELA CABEÇA O TeXTo dA Audre Lorde (Poetry IS NOT A LUXURY) E O TEXTO DA GLORIA AnZaldúa ( To(o) QueER the Writer)...

(T.N) - Ogum é orixá que rege as tecnologias né? o ferreiro, e o agricultor também: nesse caso também provedor, também alimenta. a padê (é em minúsculas mesmo) veio de um sonho partilhado, que começou quando ganhei de um amigo um livro de uma cartonera, a eloísa cartonera. no brasil conheci duas outras editoras que fazem livros com capa de papelão reciclado, em cooperativas de catadoras/es: a abadia catadora, do df, que fica na cidade estrutural; e a dulcineia catadora, de sp. há outras, mas não conheci pelos livros, ainda. essas duas sim. daí encontrei bárbara esmenia no df, ela é poeta também, bem no dia em que ganhei o livro. mostrei pra ela, sonhei alto "vamo montar 
uma editora assim?", ela topou e tamos aí: 4 títulos publicados, quase 1000 exemplares feitos (contando todos eles), mais dois títulos artesanais a serem lançados em 2017, e o primeiro impresso em gráfica. lundu, (com a vírgula mesmo, e em minúsculas também) foi o segundo livro da padê, lancei em março de 2016. tô começando a imprimir a segunda tiragem, vai ter capa diferente (era gravura, vai ser serigrafia). juntei os poemas mais amados que tinha feito em 2014/2015, deve ter algum do comecim de 2016 no meio, alguns de 2009, que é um ano muito importante pra mim, pra minha poesia, por ser o ano em que por primeira vez falo um poema pra um público majoritariamente negro, num curso de extensão na unb promovito pela profa. Denise Botelho (que agora tá na UFRPE), com participação de Lúcia Xavier; também ano em que começo a namorar a primeira mulher com quem namorei (e ficamos juntas cinco anos), então acho que esse livro foi... a reunião de uma... melhor: foi... a primeira declaração impressa sistematizada de minha obra enquanto poeta negra na diáspora e na dissidência sexual. assim, o livro num tem só poemas sobre ser sapatão nem só sobre ser negra né, e isso me lembra muito aquele texto da gloria anzaldúa (aliás Claudia falou que a tradução sai publicada esse ano!!), o que é um texto lésbico? o que é um texto negro? tenho pra mim que tudo que eu escrevo é lésbico y negro porque eu sou uma sapatão negra, afinal. lembro muito também da Witig naquela discussão do "ponto de vista: universal ou particular?", e ela falando da Djuna Barnes... esse da Wittig tá traduzido no site do confabulando (que era o tentáculo virtual do corpuscrisis e agora é o que restou dessa coletiva que foi tão potente, tão importante). http://kk2o11.confabulando. org/index.php/Main/Traduzidas, pra quem quiser ler

por que escrever? por que não né? eu às vezes acho que escrevo porque não sei desenhar. mas só às vezes. em geral eu sei, de sentir, que escrevo porque é assim que aprendi a construir história, e a me constituir enquanto sujeita. pensante. o projeto da padê, que é estético-político-afetivo mesmo como você ressaltou, é um projeto de conexão de escrituras desde a dissidência, e nessa reinauguração que tem rolado de uma mirada da diáspora como ponto de partida né, ampliando o sentido primeiro do tráfico e da exploração, às vezes até questionando esse sentido: como diz a Dionne Brand, a diáspora como esse lugar-nenhum que tem que ser feito lugar. e temos feito, eu acho. com a palavra compartilhada principalmente. a produção de textos desde sujeitxs subalternizadxs cria um mundo de referências, cria novos espelhos, constitui uma linguagem nossa, a partir da qual nos reelaboramos pra fora do confinamento que a empreitada racista, heteropatriarcal, cisnormativa, capitalista tem elaborado aqui há meio milênio. não só rompe o silenciamento, força que as escutas mudem. que os ouvidos ouçam, que os olhos leiam, que os dedos toquem, que algumas bocas se calem e reaprendam a falar antes de continuar falando. a padê é um tentaculinho nesse cefalópode gigante que é a reelaboração narrativa, epistêmica, estética de comunidades subalternizadas. e olha que depois de ler a queda do céu, de Davi Kopenawa, eu 
passei a questionar bastante a importância do gravado em peles-de-imagens viu? mas continuo publicando. acho autopublicação uma parada imprescindível pra questionar as mega-estruturas: da publicação, da narrativa, da autoria. todo mundo pode escrever. qualquer coisa pode ser publicada. inclusive, ou principalmente, as que vêm sendo escondidas, clandestinizadas.

7 - (M.S) - Para terminar mesmo... Eu TENHO LIDO MUITAS DAS SUAS POESIAS, ACOMPANHADO SUA PÁGINA NO FACEBOOK, o Palavra Pretaz, seus vídeos de performances. Aliás, adorei o "APocalipse QueER"3 ( COMO APARECE O QUEER NA SUA POÉTICA?). VOCÊ PODERIA NOS DEIXAR UMA POESIA PARA SELAR NOSSA CONVERSAR? E Diga para Nós: CoMo Conseguir os livros da PADÊ? CoMo PUBLICAR NA PADÊ?

(T.N) - como linguagem importa pra mim e pra você, vou insistir nisso aqui: a página é palavrapreta, tudo junto e em minúsculas, e o poema chama "cuíer A.P (ou 'oriki de shiva')", não é queer. é cuíer. eu sinceramente acho esse poema OK. gosto muuuuuuito mais de outros poemas meus. mas ele tem um apelo muito forte pra esse momento político desconstrutivo que tamos vivendo né? que é um momento bem shivaísta mesmo. e tudo bem. mas me interessa pensar também no que vamos plantar, porque tem muita terra preta embaixo de todo concreto. como vamos nadar. porque tem muito rio afogado embaixo de asfalto. como vamos dançar. porque vai ter muita música depois

$\overline{{ }^{2} \text { https://www.facebook.com/palavrapreta/ }}$ ${ }^{3} \mathrm{https} / /$ www.youtube.com/watch?v=KAcdmfd7psM\&t=3s que os gritos de briga diminuírem um pouco. né? assim aparece o cuíer na minha poética: como uma brecha terceromundista, inflamada, apaixonada, vulcânica, de se montar, talvez de se desmontar-pra-se-remontar, deixando tudo meio esquisito. tirando do lugar. trabalho de Exu, que nem naquele itan que ouvi uma vez, que depois que Orunmilá cria o mundo e cada coisa tem seu nome, Exu troca o nome de todas as coisas, dando início ao movimento - pela bagunça, pela desestabilização. o que é isso se não a poesia né? chamar cada coisa de um nome outro, fazendo ele próprio daquilo, ali, naquele contexto. torcer e distorcer os sentidos. o "cuíer A.P." é um lado de um prisma, que em outro lado tem "lundu" (o poema que dá título), tem "queerlombismo" que depois virou "cuíerlombismo", e que finalmente tem "cuíer paradiso", e vai ter outros mais. cuíer na minha poesia às vezes é tema, às vezes inspiração, às vezes só o chão mesmo de onde parto porque sou essa pessoa: e o chão de onde partimos é tão importante. a firmeza do movediço, no caso de desestabilizar identitariamente y de bagunçar a linguagem também, essa certeza frágil que temos como a única e mais especial coisa que nos difere de pessoas não-humanas. mas veja aí os pássaros todos voando, as águas todas correndo, o vento todo soprando, cada coisa em seu lugar. e a gente se debatendo com os termos, com os significados, será que é uma coisa tão importante assim, mesmo?

pra publicar na padê tem que emocionar as editoras, que somos eu e bárbara. a gente publica o que A M A, o que mexeu muito ler. então geralmente convidamos as pessoas que publicamos. algumas pessoas enviaram 
imeio com manuscritos, e amamos também, e vai rolar: pade.editorial@gmail.com

dá pra pedir os livros por imeio também. ou pela página no facebook. e nos próximos meses vamos inaugurar nosso site, quando vai ser publicada a entrevista? acho que até lá já dá tempo de divulgar esse link também jejejejejeje gracias marcelo pela prosa! te vejo na floresta?

asaana, ou: sobreviver o fel

mientras los ojos de criança destilavam

ódio

aprendido no ventre, aprendizes do vento encruzilhavam monocromias penta tônicas, entoando uma velha canção escrava:

"hoje

não tem boca pra se beijar não tem alma pra se lavar nem tem vida pra se viver mas tem dinheiro pra se contar de terno e gravata, seu pai agradar levar sua filha pro mundo perder é o céu da boca do inferno esperando você"

ancestral (o tempo) os

continente escur

os corações

inquebrantáveis a pele

herdada

(um presente)

sabem que:

ralé não dança valsa vienense, no si puede bailar

la partitura

blanca

quem ia correr o risco de esquecer o próprio destino, Odú - olhos transbordantes de Irêesquecer

Orunmilá vindo até aqui pra ensinar

o tambor?

(tecnologia ancestral de re

compor)

esquecer o pacto: é se

perder.

pero a eso mira, mira la niña / su odio contra nosotres / su miedo de la gente scharwzen / su rabia de ensuciarse / la ciudad tan limpia es vieja y imperial / la linea del autobus tiene una topografía colonial / la arquitectura espectral de las calles mira mira a todo eso, cariño, y luego olvidate, no te ubicas en la

dolor:

a boca da criança escorria veneno aprendido no sêmen

tão temprano!

y eu contra minhas têmporas sentindo mas

desaprendendo o ódio por ela mas staring back

o ônibus cheio, você vestia

Funfun, o dia Dudu, 
Marcelo Spitzner, Tatiana Nascimento

sua mão

me amaciava os caminhos, Odú:

amor,

(no te preocupes.)

amor o que se tinha de beber

contraquele

nó na garganta: "asaana?"

“asaana!”

"contregum

contresses ritmo": sádico -

500 anos de garantia, pode provar:

asaanaé mergulhar

(y cuidate,

cariño).

[pra amoako boafo, junho de 2016, viena]

Recebido para publicação em 30 nov. 2017.

Aceito para publicação em 20 jan. 2018. 